\title{
Increased Severity of Stroke in CB1 Cannabinoid Receptor Knock-Out Mice
}

\author{
Sophie Parmentier-Batteur, ${ }^{1}$ Kunlin Jin, ${ }^{1}$ Xiao Ou Mao, ${ }^{1}$ Lin Xie, ${ }^{1}$ and David A. Greenberg ${ }^{1,2}$ \\ ${ }^{1}$ Buck Institute for Age Research, Novato, California 94945, and '2Department of Neurology, University of California, \\ San Francisco, California 94143
}

Endogenous cannabinoid signaling pathways have been implicated in protection of the brain from hypoxia, ischemia, and trauma, but the mechanism for these protective effects is uncertain. We found that in CB1 cannabinoid receptor knock-out mice, mortality from permanent focal cerebral ischemia was increased, infarct size and neurological deficits after transient focal cerebral ischemia were more severe, cerebral blood flow in the ischemic penumbra during reperfusion was reduced, and
NMDA neurotoxicity was increased compared with wild-type littermates. These findings indicate that endogenous cannabinoid signaling pathways protect mice from ischemic stroke by a mechanism that involves CB1 receptors, and suggest that both blood vessels and neurons may be targets of this protective effect.

Key words: ischemia; cannabinoid; CB1 receptor; stroke; cerebral blood flow; NMDA
Cannabinoids, which include the marijuana constituent $\Delta^{9}$ tetrahydrocannabinol (Gaoni and Mechoulam, 1964) and endogenous cannabinoids (endocannabinoids) produced in the brain (Devane et al., 1992; Stella et al., 1997), exert many of their effects through the G-protein-coupled CB1 receptor (Matsuda et al., 1990). Cannabinoids reduce neuronal death from a variety of insults, including excitotoxicity (Shen and Thayer, 1998), oxidative stress (Hampson et al., 1998), hypoxia (Sinor et al., 2000), ischemic stroke (Nagayama et al., 1999), and trauma (Panikashvili et al., 2001), but the mechanism that underlies their neuroprotective action is uncertain.

We reported previously that the cannabinoid agonist $R(+)$ 2,3-dihydro-5-methyl-3-[(morpholinyl)methyl]pyrrolo[1,2,3-de]-1,4benzoxazin-yl-1-naphthalenylmethanone mesylate $[R(+)$-WIN 55212-2] decreased hippocampal neuronal loss after transient global cerebral ischemia and reduced infarct volume after permanent focal cerebral ischemia induced by middle cerebral artery (MCA) occlusion in rats (Nagayama et al., 1999). These effects were stereoselective for WIN 55212 isomers and were inhibited by the CB1 cannabinoid receptor antagonist $N$-(piperidin-1-yl)5-(4-chlorophenyl)-1-(2,4-dichlorophenyl)-4-methyl-1H-pyrazole3-carboxamidehydrochloride (SR141716A), consistent with CB1mediated effects. Panikashvili et al. (2001) found that the endocannabinoid 2-arachidonoyl glycerol improved histological and functional outcome after closed head injury in mice, including a reduction in the size of trauma-related cerebral infarcts, and that these effects were also attenuated by SR141716A.

Although the pharmacological features of neuroprotection from cerebral ischemia (Nagayama et al., 1999) and closed head trauma (Panikashvili et al., 2001) are consistent with CB1 receptor-mediated effects, recent evidence suggests that non-CB1

Received June 21, 2002; revised Sept. 3, 2002; accepted Sept. 9, 2002.

This work was supported by National Institutes of Health Grant NS39912 and by the Buck Institute for Age Research. We thank C. Ledent for providing CB1 knock-out mice.

Correspondence should be addressed to Dr. David A. Greenberg, Buck Institute for Age Research, 8001 Redwood Boulevard, Novato, CA 94945. E-mail: dgreenberg@ buckinstitute.org.

Copyright (C) 2002 Society for Neuroscience $\quad 0270-6474 / 02 / 229771-05 \$ 15.00 / 0$ receptors with similar pharmacology may exist in the brain. These include a G-protein-coupled receptor in mouse brain membranes that is activated by $\mathrm{R}(+)$-W IN 555212-2 and by the endocannabinoid anandamide, but not by other CB1 agonists, and is insensitive to SR141716A (Jarai et al., 1999; Breivogel et al., 2001), and a presynaptic receptor in hippocampal slices from CB1 knock-out mice that is activated by $\mathrm{R}(+)$-WIN 555212-2 and blocked by SR141716A and that inhibits glutamate release (Jarai et al., 1999; Breivogel et al., 2001). The availability of CB1 receptor knock-out mice in which numerous physiological effects of cannabinoids are absent (Ledent et al., 1999) provides an opportunity to address directly whether the CB1 receptor mediates endogenous neuroprotection from ischemia and, if so, to identify the cellular targets involved.

\section{MATERIALS AND METHODS}

Animals. CB1 knock-out, heterozygous, and wild-type mice bred for at least five generations on a CD1 background were provided by Ledent et al. (1999) and were used to breed the mice used in his study. Experiments were approved by local committee review and were conducted according to policies on the use of animals of the Society for Neuroscience.

CB1 receptor expression. Genotyping was performed according to the protocol of Ledent et al. (1999), using the PCR primers 5'-CATCATCACAGATTTCTATGTAC-3' and 5'-GAGGTGCCAGGAGGGAACC-3', which amplify a $366 \mathrm{bp}$ band from the wild-type CB1 allele and 5'-GATCCAGAACATCAGGTAGG-3' and 5'-AAGGAAGGGTGAGAACAGAG-3', which amplify a 521 bp band from the mutated CB1 allele. Western blotting and immunohistochemistry were conducted as described in detail previously (Sun et al., 2001). For Western blots, 25 $\mu \mathrm{g}$ of forebrain membrane protein was electrophoresed and transferred to polyvinyldifluoridine membranes, which were blocked with $5 \%$ nonfat dried milk in PBS plus $0.1 \%$ Tween 20, and reacted with affinity-purified rabbit polyclonal anti-CB1 (1:100; Calbiochem, San Diego, CA) for $4 \mathrm{hr}$ at room temperature. Blots were incubated with biotinylated anti-rabbit IgG (1:2000; Santa Cruz Biotechnology, Santa Cruz, CA) and streptavidin HRP-conjugated antibody (Vector Laboratories, Burlingame, CA) for $1 \mathrm{hr}$ in each and visualized by chemiluminescence. For immunohistochemistry, the primary antibodies were affinity-purified rabbit polyclonal anti-CB1 (1:200; Calbiochem), mouse monoclonal anti-neuronalspecific nuclear protein (NeuN) (1:500; Chemicon, Temecula, CA), mouse monoclonal anti- $\alpha_{2}$ (vascular smooth muscle) actin (1:100; Maine Biotechnology, Portland, ME), and affinity-purified goat anti-E-selectin (1:100; Santa Cruz Biotechnology). The secondary antibodies were 

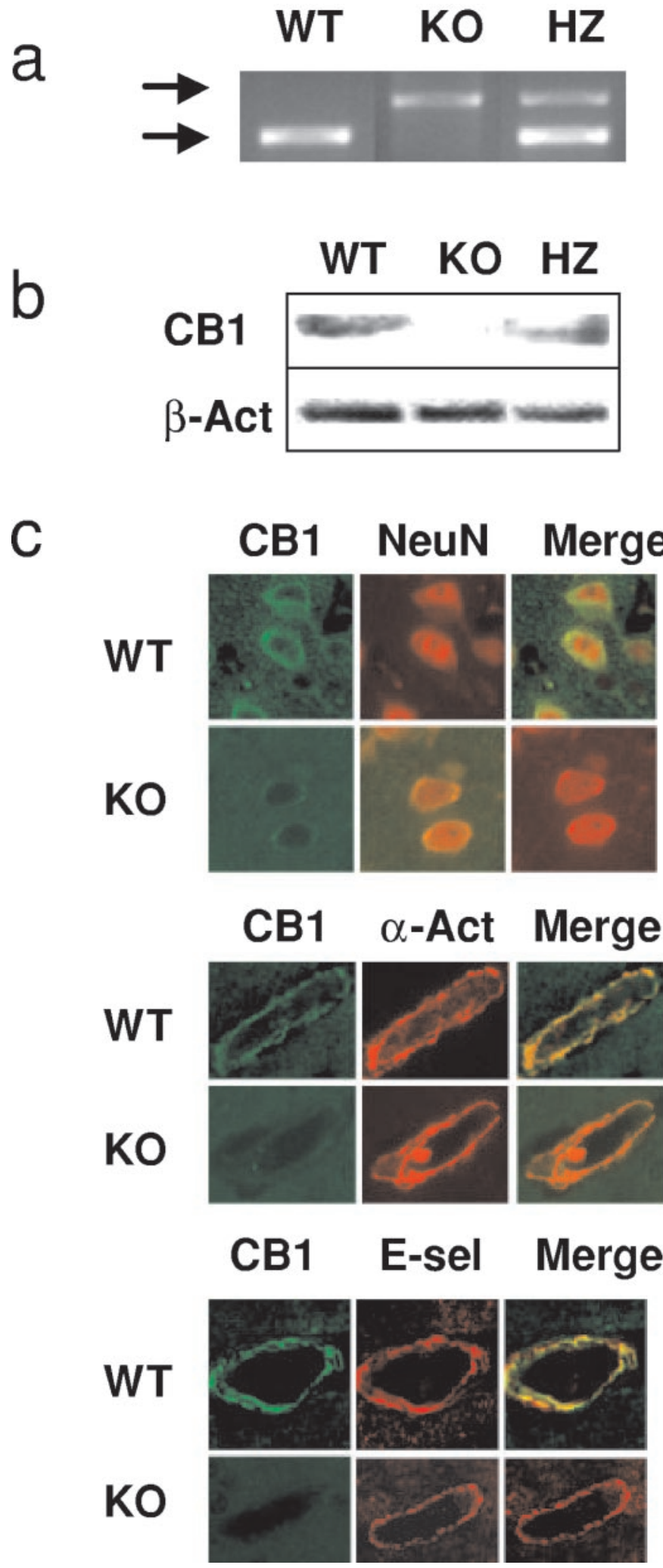

Figure 1. Phenotypic features of CB1 receptor knock-out mice. $a$, Genotype analysis documenting absence of the wild-type $(W T) \mathrm{CB} 1^{+/+}$ allele (bottom arrow) and presence of the mutated [knock-out $(K O)$ ] $\mathrm{CB} 1^{-1-}$ allele (top arrow) in CB1 knock-out mice. $H Z$, Heterozygote. $b$, Western blots confirming the absence of CB1 protein $\left(M_{\mathrm{r}}, \sim 53 \mathrm{kDa}\right)$ in forebrains of knock-out mice. Each lane contains a pooled protein sample from three mice. Blots were stripped and rehybridized with anti- $\beta$-actin $(\beta-A c t)$ to control for variations in protein application or transfer.
Table 1. Physiological and mortality measurements associated with transient cerebral ischemia in wild-type and CB1 mutant mice

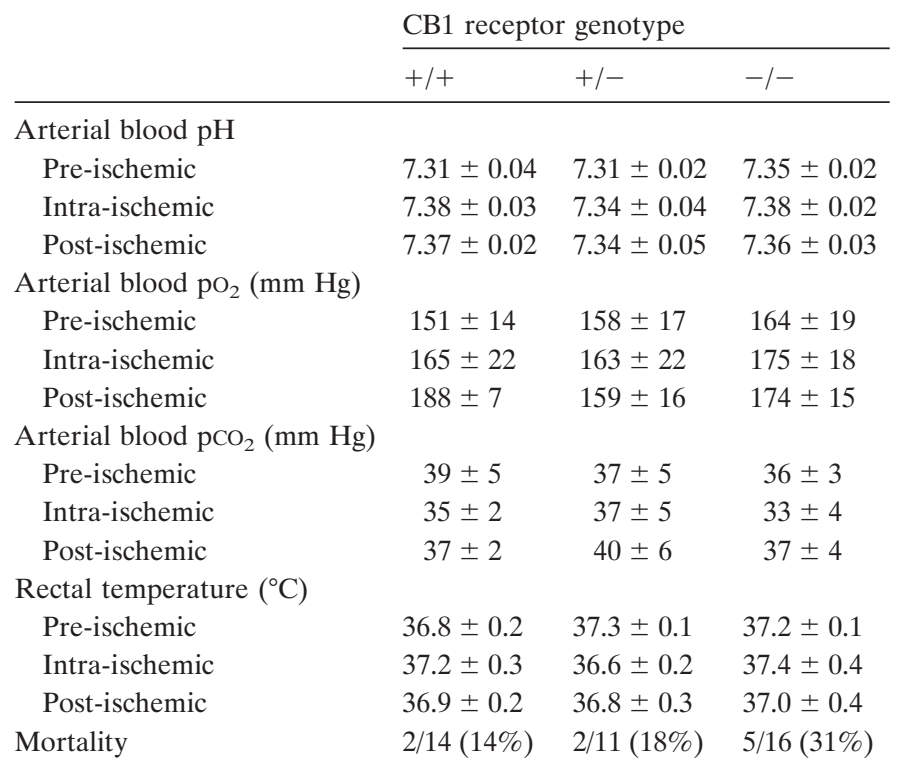

Physiological measurements were made immediately before (pre-ischemic), $10 \mathrm{~min}$ after the onset of (intra-ischemic), or $10 \mathrm{~min}$ after termination of (post-ischemic) 20 min of MCA occlusion followed by reperfusion. Mortality was measured at $24 \mathrm{hr}$. Data are means $\pm \operatorname{SEM}(n=5)$.

FITC-conjugated goat anti-rabbit IgG (1:200; Vector Laboratories) and rhodamine-conjugated donkey anti-mouse and anti-goat $\operatorname{IgG}(1: 200$; Jackson ImmunoResearch, West Grove, PA). Controls included omitting primary or secondary antibodies.

Ischemia model. Male mice (30-35 gm) were anesthetized with $1.5 \%$ isoflurane in $70 \% \mathrm{~N}_{2} \mathrm{O} / 30 \% \mathrm{O}_{2}$. Rectal temperature was maintained at $37.0 \pm 0.5^{\circ} \mathrm{C}$ with a thermostat-controlled heating blanket. The left external carotid artery was ligated with 6-0 silk suture, and its branches were electrocoagulated. A 5-0 monofilament surgical nylon suture with a heat-blunted tip was introduced into the left internal carotid artery through the stump of the external carotid and advanced $12 \mathrm{~mm}$ past the common carotid artery bifurcation to occlude the left MCA. The left common carotid artery was also occluded during the period of MCA occlusion. The filament was sutured in place (permanent ischemia) or withdrawn $20 \mathrm{~min}$ later (transient ischemia). Regional cerebral blood flow (rCBF) was measured by laser-Doppler flowmetry with a probe (Vasamedic, St. Paul, MN) placed through a burr hole drilled $1.5 \mathrm{~mm}$ lateral to the midline and $1.7 \mathrm{~mm}$ anterior to the lambda. This location was based on previous reports (Iadecola et al., 2001) and was confirmed in preliminary experiments to correspond to the brain region that is recruited into infarction in CB1 knock-out mice. Infarct area was measured on $2 \mathrm{~mm}$ coronal brain sections, which were immersed in $2 \%$ 2,3,5-triphenyltetrazolium hydrochloride (TTC) in PBS for $20 \mathrm{~min}$ at $37^{\circ} \mathrm{C}$ and then fixed overnight at $4^{\circ} \mathrm{C}$ in $4 \%$ paraformaldehyde (Bederson et al., 1986b). Infarct volume was calculated by integrating the infarction areas, corrected for edema (Lin et al., 1993). Neurological function was assessed using a standard scoring system: 0 , no deficit; 1 , failure to extend right forepaw; 2 , circling to right; 3 , falling to right; 4 , inability to walk spontaneously (Bederson et al., 1986a).

Intracerebral NMDA administration. Neuronal excitotoxicity was induced in nonischemic animals by intracerebral injection of $20 \mathrm{nmol}$ of NMDA in $200 \mathrm{nl}$ of sterile PBS into the parietal cortex at a site $1.5 \mathrm{~mm}$ caudal to bregma, $4.0 \mathrm{~mm}$ from the midline, and $0.8 \mathrm{~mm}$ below the dural

$\longleftarrow$

$c$, Immunohistochemical localization of CB1 receptors to NeuN-labeled neurons, $\alpha$-actin-labeled vascular smooth muscle $(\alpha-A c t)$ and E-selectinlabeled endothelium (E-sel) of wild-type (top) but not CB1 knock-out (bottom) mice. Data are representative blots or fields from at least three independent experiments per panel. 

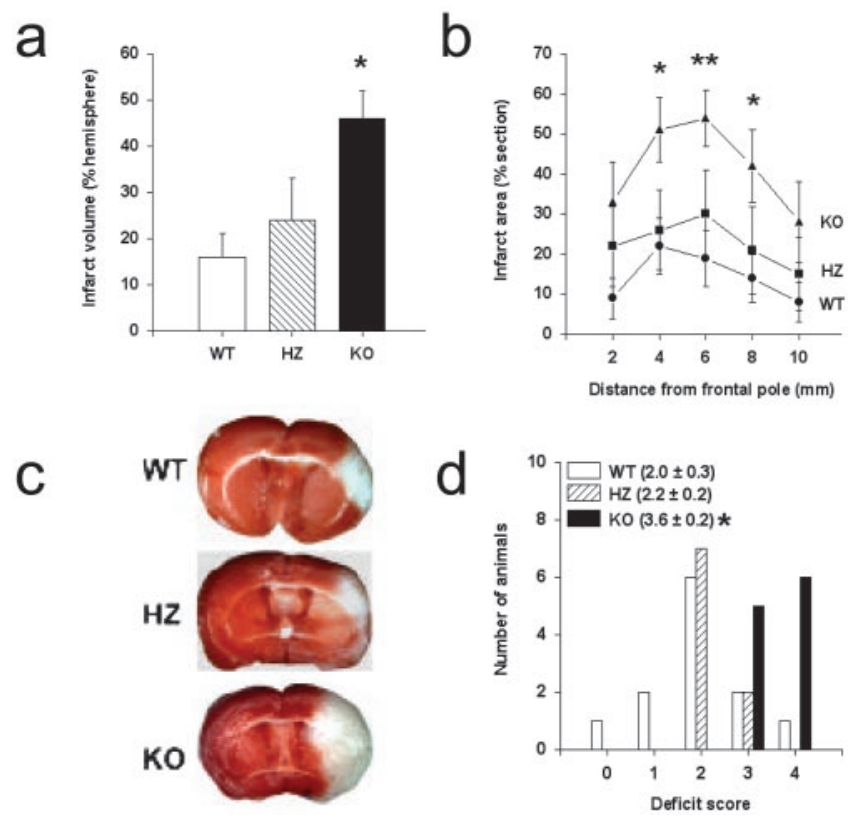

Figure 2. Brain infarct size and neurological deficit in wild-type (WT), $\mathrm{CB} 1^{+1-}$ heterozygous $(H Z)$, and $\mathrm{CB} 1^{-1-}$ knock-out $(K O)$ mice. The MCA was occluded for 20 min followed by reperfusion for $24 \mathrm{hr}$, and infarct volume $(a)$ and infarct area $(b)$ on TTC-stained coronal brain sections taken at the indicated distances from the frontal pole $(c)$ were measured as described in Materials and Methods, as was the neurological deficit score $(d)$. Data are means \pm SEM from 8 to 12 animals. ${ }^{*} p<0.05$; ${ }^{* *} p<0.01$ relative to wild type ( $a, d$, ANOVA followed by Fisher's PLSD test; $b$, Kruskal-Wallis test followed by Mann-Whitney $U$ test).

surface. After $24 \mathrm{hr}, 30 \mu \mathrm{m}$ coronal brain sections were stained with hematoxylin to delineate the resulting lesion.

Data analysis. Quantitative data were expressed as mean \pm SEM from at least three experiments. ANOVA and Student's $t$ test were used for statistical analysis, with $p$ values of $<0.05$ considered significant.

\section{RESULTS}

The brains of CB1 knock-out mice failed to express CB1 mRNA and protein as measured by PCR genotyping and Western blotting, and immunohistochemical analysis of cerebral cortical sections showed that CB1 immunoreactivity, which was localized to neurons and blood vessels of wild-type mouse brain, was absent from knock-out mice (Fig. 1). Nevertheless, the macroscopic anatomy of the brain and major cerebral blood vessels was normal in knock-out mice (data not shown).

In initial studies, permanent occlusion of the left MCA with a suture was associated with a fivefold higher mortality at $24 \mathrm{hr}$ in knock-out mice (five of six mice; $83 \%$ ) than in wild-type mice (one of six; 17\%). To reduce mortality and better assess the effect of CB1 knock-out on the size of cerebral infarcts, we reduced the duration of MCA occlusion to $20 \mathrm{~min}$, followed by reperfusion for $24 \mathrm{hr}$. Under these conditions, there was no difference between wild-type and knock-out mice with regard to arterial blood gas measurements or temperature (Table 1). Acute postischemic mortality in knock-out mice was still approximately twice that seen in wild-type mice, but a sufficient number of mice survived in whom to measure infarct size. Infarct volume, determined using the vital dye TTC to delineate surviving tissue (Bederson et al., 1986b) and confirmed by cresyl violet staining of fixed sections (data not shown), was increased 0.5-fold in CB1 heterozygotes and threefold in knock-out mice, and we observed this difference throughout the linear extent of the infarct (Fig. 2). Global neu-
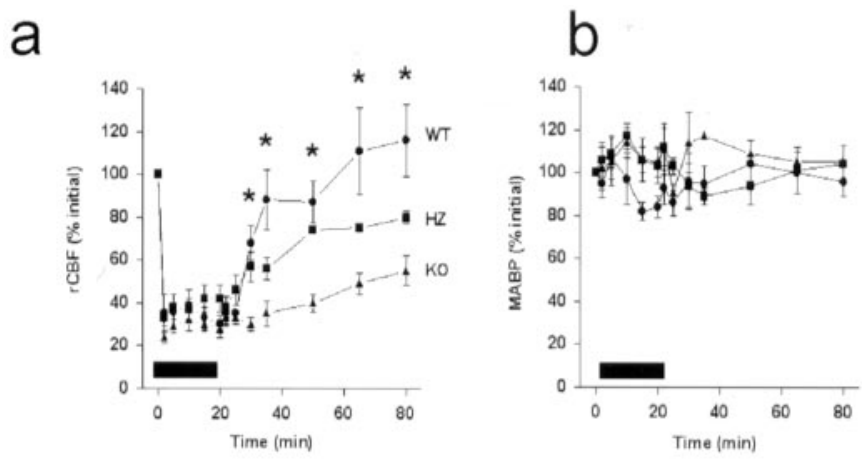

C
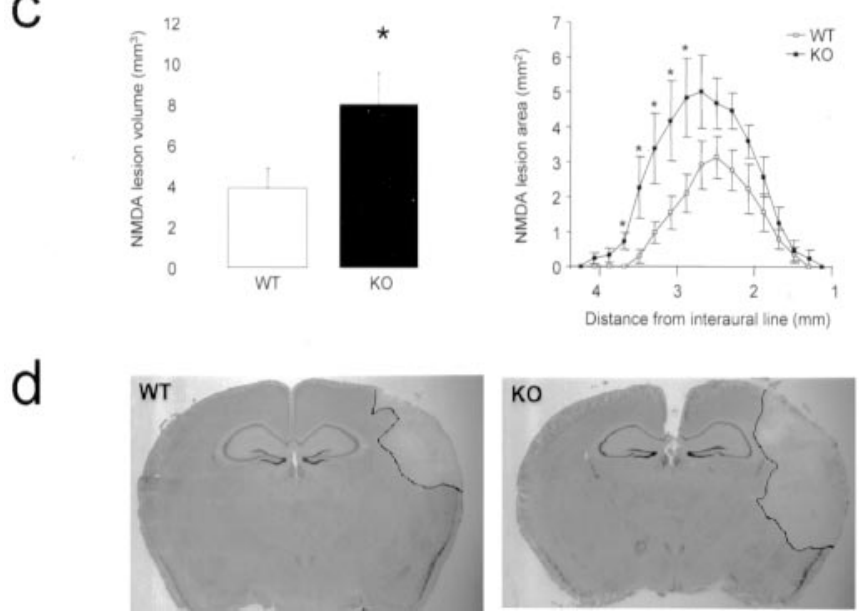

Figure 3. Vascular and neuronal basis for increased severity of cerebral ischemia in CB1 receptor knock-out mice. The MCA was occluded for 20 $\min (a, b$, bars $)$, and $\mathrm{rCBF}(a)$ and MABP $(b)$ were monitored continuously in wild-type $(W T, \bullet), \mathrm{CB} 1^{+/-}$heterozygous $(H Z, \mathbf{\square})$, and $\mathrm{CB} 1^{-/-}$ knock-out $(K O, \boldsymbol{\Delta})$ mice. $c$, NMDA $(20 \mathrm{nmol})$ was injected into the parietal cortex of WT ( $\square)$ and KO ( $\square$ ) mice; the volume (left) and area at multiple coronal levels (right) of the resulting excitotoxic lesion were measured $24 \mathrm{hr}$ later by staining with hematoxylin and measuring the unstained region (outlined in $d$ ). Data are means \pm SEM from five $(a, b)$ or six (c) animals or representative sections from six brains per condition (d). ${ }^{*} p<0.05$ for knock-out relative to wild type ( $a, b$, ANOVA followed by Fisher's PLSD test; $c$, two-tailed Student's $t$ test).

rological score, which reflects the severity of functional brain injury after cerebral ischemia (Yang et al., 1994), was also more severely impaired in knock-out compared with wild-type mice.

The presence of vascular CB1 receptors in the brains of our wild-type mice (Fig. 1) suggested the possibility that loss of these receptors in $\mathrm{CB} 1$ knock-out mice might contribute to the increase in infarct size that we observed. To test this possibility, we first compared $\mathrm{rCBF}$ in the ischemic penumbra, or border zone, during temporary MCA occlusion in wild-type and CB1 knock-out mice. During ischemia, blood flow in the penumbra is reduced but not eliminated, and neuronal dysfunction is potentially reversible; therefore, the ultimate fate of neurons in the penumbra is a major determinant of infarct size and neurological outcome after stroke (Sharp et al., 2000). After MCA occlusion, rCBF in the ischemic penumbra was reduced to similar levels in wild-type and $\mathrm{CB} 1$ knock-out mice; however, whereas $\mathrm{rCBF}$ was restored to basal levels during reperfusion in wild-type mice, it remained low in CB1 knock-out mice (Fig. 3). This appeared to result from a direct effect on the cerebral vasculature, and not from systemic hypotension, because mean arterial blood pressure (MABP) was equivalent in wild-type and CB1 knock-out mice. 
CB1 receptors are also found on neurons, where their expression is increased in the ischemic penumbra after experimental stroke in rats (Jin et al., 2000). To test whether the loss of neuronal CB1 receptors also contributed to the more severe effects of cerebral ischemia in CB1 knock-out mice, we compared the extent of NMDA excitotoxicity, a lesion that shares pathophysiological features with cerebral ischemia (Simon et al., 1984) but which affects neurons directly, in wild-type and CB1 knockout mice. Direct microinjection of $20 \mathrm{nmol}$ of NMDA into the cerebral cortex of $\mathrm{CB} 1$ knock-out mice produced excitotoxic lesions that were approximately twice the size of lesions in nonischemic wild-type mice. Therefore, the increased infarct size in CB1 knock-out mice may result partly from enhanced sensitivity to neuronal excitotoxicity.

\section{DISCUSSION}

The major finding of this study is that cerebral ischemia has more severe effects in CB1 knock-out than in wild-type mice, which appear to be caused by the loss of both cerebral vascular and neuronal $\mathrm{CB} 1$ receptors.

The protective effects of cannabinoids against cerebral ischemia and trauma in vivo have been thought to be mediated through CB1 receptors, because these effects are produced in a stereoselective manner by isomeric cannabinoid agonists and are blocked by CB1 antagonists (Nagayama et al., 1999; Panikashvili et al., 2001). However, additional classes of cannabinoid receptors with CB1-like pharmacology are likely to exist (Jarai et al., 1999; Breivogel et al., 2001), and several studies of cannabinoidinduced neuroprotection in in vitro cell-culture systems have reported effects that are not receptor-mediated (Hampson et al., 1998; Nagayama et al., 1999; Sinor et al., 2000). The reason for this latter discrepancy is unclear, but it could be related to the fact that cerebral CB1 receptors are located not only on neurons but also on cerebrovascular smooth muscle and endothelial cells (Hillard, 2000), where their activation promotes vasodilation (Gebremedhin et al., 1999) and increases cerebral blood flow (Hillard, 2000). Because blood vessels are absent from cortical neuron cultures, a neuroprotective effect that was mediated partly through vascular effects of cannabinoids (Hillard, 2000), such as an increase in blood flow to ischemic tissue at risk for infarction, might be less evident in such systems.

CB1 receptors were expressed by neurons, vascular smooth muscle cells, and endothelial cells of our wild-type mice but were absent in CB1 knock-out mice, which developed approximately threefold larger cerebral infarcts after transient occlusion of the MCA. These larger infarcts were associated with correspondingly more severe functional deficits on behavioral testing. The finding that cerebral ischemia is exacerbated in CB1 receptor knock-out mice is consistent with an endogenous neuroprotective role for the endocannabinoid signaling system in the brain and with our previous finding that administration of exogenous cannabinoids reduces ischemic neuronal injury after both global and focal cerebral ischemia (Nagayama et al., 1999). In that study, the pharmacological features of neuroprotection suggested a CB1 receptor-mediated effect, but the availability of $\mathrm{CB} 1$ receptor knock-out mice provided an opportunity to test more directly whether endocannabinoid-CB1 interactions mediate neuroprotection in ischemia.

The dysregulation of $\mathrm{rCBF}$ that we observed during reperfusion in the ischemic penumbra of CB1 knock-out mice suggests that in the cerebral vasculature after stroke, endogenous cannabinoid signaling through CB1 receptors normally acts to enhance blood flow and promote cell survival. This is consistent with the ability of cannabinoids to increase cerebral blood flow (Hillard, 2000) and with the proposed role of vascular mechanisms in the protective effect of cannabinoids in head trauma, which may involve antagonism of vasoconstriction induced by endothelin-1 (Panikashvili et al., 2001). Nevertheless, caution is warranted in the interpretation of these results insofar as absolute values for rCBF in wild-type, heterozygous, and knock-out animals were not measured. The observation that brain lesions induced by direct injection of NMDA are more severe in CB1 knock-out mice suggests that neuronal $\mathrm{CB} 1$ receptors may also be involved in protection from ischemia, with the caveat that excitotoxic effects of NMDA can have a vascular component as well (Dietrich et al., 1992; Globus et al., 1995). In the absence of CB1 receptors, not only these direct protective effects but also the ischemia-induced upregulation of neuronal CB1 receptor expression (Jin et al., 2000) would be lost, further compromising the capacity of the brain to adapt to and survive ischemia.

Neuronal CB1 receptors are thought to reside primarily on presynaptic nerve terminals, where their activation inhibits voltage-gated calcium channels, and their neuroprotective effect in ischemia could be mediated partly through the inhibition of depolarization-induced glutamate release (Shen et al., 1996). How the absence of CB1 receptors exacerbates the excitotoxicity of directly applied NMDA is unclear, but the more severe NMDA-induced injury in CB1 knock-out mice suggests that endogenous cannabinoid signaling can also regulate excitotoxicity at a step beyond glutamate release. Because CB1 receptor activation is coupled to a variety of effectors, including ion channels, adenylate cyclase, and protein kinases (Pertwee, 1997), there are numerous signaling pathways through which such an effect might occur.

Clinical stroke, which usually results from cerebral ischemia, is a common and frequently incapacitating problem for which satisfactory treatment is generally unavailable. Identifying new endogenous systems that mitigate ischemic brain injury through effects on neurons, blood vessels, or both (such as the endocannabinoid signaling pathway) may help to guide the search for improved therapies.

\section{REFERENCES}

Bederson JB, Pitts LH, Tsuji M, Nishimura MC, Davis RL, Bartkowski H (1986a) Rat middle cerebral artery occlusion: evaluation of the model and development of a neurologic examination. Stroke 17:472-476.

Bederson JB, Pitts LH, Germano IM, Nishimura MC, Davis RL, Bartkowski HM (1986b) Evaluation of 2,3,5-triphenyltetrazolium chloride as a stain for detection and quantification of experimental cerebral infarction in rats. Stroke 17:1304-1307.

Breivogel CS, Griffin G, Di Marzo V, Martin BR (2001) Evidence for a new $G$ protein-coupled cannabinoid receptor in mouse brain. Mol Pharmacol 60:155-163.

Devane WA, Hanus L, Breuer A, Pertwee RG, Stevenson LA, Griffin G, Gibson D, Mandelbaum A, Etinger A, Mechoulam R (1992) Isolation and structure of a brain constituent that binds to the cannabinoid receptor. Science 258:1946-1949.

Dietrich WD, Alonso O, Halley M, Busto R, Globus MY (1992) Intraventricular infusion of $N$-methyl-D-aspartate. I. Acute blood-brain barrier consequences. Acta Neuropathol (Berl) 84:621-629.

Gaoni Y, Mechoulam R (1964) Isolation, structure, and partial synthesis of an active constituent of hashish. J Am Chem Soc 86:1646-1647.

Gebremedhin D, Lange AR, Campbell WB, Hillard CJ, Harder DR (1999) Cannabinoid $\mathrm{CB}_{1}$ receptor of cat cerebral arterial muscle functions to inhibit L-type $\mathrm{Ca}^{2+}$ channel current. Am J Physiol 276:H2085-H2093.

Globus MY, Prado R, Sanchez-Ramos J, Z hao W, Dietrich WD, Busto R, Ginsberg MD (1995) A dual role for nitric oxide in NMDA-mediated toxicity in vivo. J Cereb Blood Flow Metab 15:904-913.

Hampson AJ, Grimaldi M, Axelrod J, Wink D (1998) Cannabidiol and $(-) \Delta 9$-tetrahydrocannabinol are neuroprotective antioxidants. Proc Natl Acad Sci USA 95:8268-8273. 
Hillard CJ (2000) Endocannabinoids and vascular function. J Pharmacol Exp Ther 294:27-32.

Iadecola C, Sugimoto K, Niwa K, Kazama K, Ross ME (2001) Increased susceptibility to ischemic brain injury in cyclooxygenase-1deficient mice. J Cereb Blood Flow Metab 21:1436-1441.

Jarai Z, Wagner JA, Varga K, Lake KD, Compton DR, Martin BR, Zimmer AM, Bonner TI, Buckley NE, Mezey E, Razdan RK, Zimmer A, Kunos G (1999) Cannabinoid-induced mesenteric vasodilation through an endothelial site distinct from CB1 or CB2 receptors. Proc Natl Acad Sci USA 96:14136-14141.

Jin KL, Mao XO, Goldsmith PC, Greenberg DA (2000) CB1 cannabinoid receptor induction in experimental stroke. Ann Neurol 48:257-261.

Ledent C, Valverde O, Cossu G, Petitet F, Aubert J-F, Beslot F, Böhme GA, Imperato A, Pedrazzini T, Roques BP, Vassart G, Fratta W, Parmentier M (1999) Unresponsiveness to cannabinoids and reduced addictive effects of opiates in CB1 receptor knockout mice. Science 283:401-404.

Lin TN, He YY, Wu G, Khan M, Hsu CY (1993) Effect of brain edema on infarct volume in a focal cerebral ischemia model in rats. Stroke 24:117-121.

Matsuda LA, Lolait SJ, Brownstein MJ, Young AC, Bonner TI (1990) Structure of a cannabinoid receptor and functional expression of the cloned cDNA. Nature 346:561-564.

Nagayama T, Sinor AD, Simon RP, Chen J, Graham S, Jin K, Greenberg DA (1999) Cannabinoids and neuroprotection from global and focal cerebral ischemia and in vitro. J Neurosci 19:2987-2995.

Panikashvili D, Simeonidou C, Ben-Shabat S, Hanus L, Breuer A,
Mechoulam R, Shohami E (2001) An endogenous cannabinoid (2$\mathrm{AG}$ ) is neuroprotective after brain injury. Nature 413:527-531.

Pertwee RG (1997) Pharmacology of cannabinoid CB1 and CB2 receptors. Pharmacol Ther 74:129-180.

Sharp FR, Lu A, Tang Y, Millhorn DE (2000) Multiple molecular penumbras after focal cerebral ischemia. J Cereb Blood Flow Metab 20:1011-1032.

Shen M, Thayer SA (1998) Cannabinoid receptor agonists protect cultured rat hippocampal neurons from excitotoxicity. Mol Pharmacol $54: 459-462$.

Shen M, Piser TM, Seybold VS, Thayer SA (1996) Cannabinoid receptor agonists inhibit glutamatergic synaptic transmission in rat hippocampal cultures. J Neurosci 16:4322-4334.

Simon RP, Swan JH, Griffiths T, Meldrum BS (1984) Blockade of $N$-methyl-D-aspartate receptors may protect against ischemic damage in the brain. Science 226:850-852.

Sinor AD, Irvin SM, Greenberg DA (2000) Endocannabinoids protect cerebral cortical neurons from in vitro ischemia in rats. Neurosci Lett 278:157-160.

Stella N, Schweitzer P, Piomelli D (1997) A second endogenous cannabinoid that modulates long-term potentiation. Nature 388:773-778.

Sun Y, Jin K, Mao XO, Zhu Y, Greenberg DA (2001) Neuroglobin is upregulated by and protects neurons from hypoxic-ischemic injury. Proc Natl Acad Sci USA 98:15306-15311.

Yang G, Chan PH, Chen J, Carlson E, Chen SF, Weinstein P, Epstein CJ, Kamii H (1994) Human copper-zinc superoxide dismutase transgenic mice are highly resistant to reperfusion injury after focal cerebral ischemia. Stroke 25:165-170. 